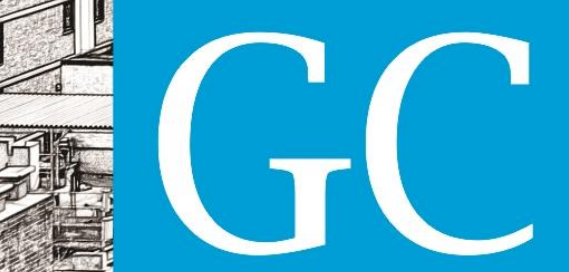

Revista Nacional de

\title{
Planejamento Urbano e Educação Ambiental: Caminhos e Perspectivas para o Desenvolvimento Sustentável nas Cidades
}

Urban planning and environmental education: paths and perspectives for sustainable development in cities

Planeamiento urbano y educación ambiental: caminos y perspectivas para el desarrollo sostenible en las ciudades

Tomás de Albuquerque Lapa Professor Titular do Programa de Pós-Graduação em Desenvolvimento Urbano (MDU/UFPE) Coordenador do Laboratório de Estudos Periurbanos - LEPUR thlapa@hotmail.com

Josimar Vieira dos Reis Doutorando em Desenvolvimento Urbano (MDU/UFPE) prej86@gmail.com

Fabrício Martins Silva Mestrando em Desenvolvimento Urbano (MDU/UFPE) fabriciolaw@gmail.com

Rubens Felipe de Paula Trajano Graduando em Arquitetura e Urbanismo/UFPE rubensfpt@gmail.com

Cecília Sampaio Sá Graduando em Arquitetura e Urbanismo/UFPE ceciliasampaiosa@gmail.com

Ícaro dos Santos Barros Correia Graduando em Arquitetura e Urbanismo/UFPE icaro.barros1998@gmail.com 


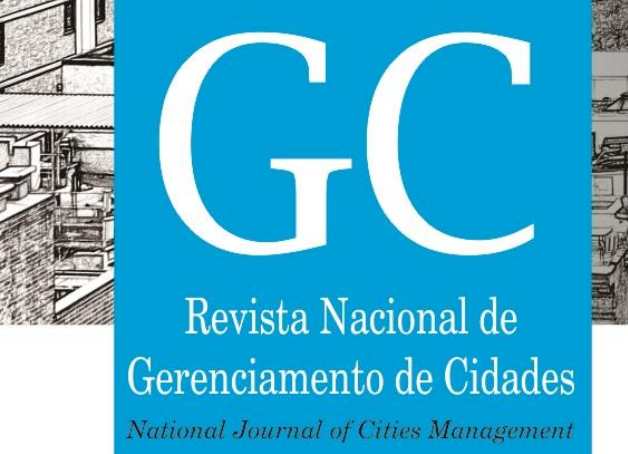

\section{RESUMO}

$\mathrm{O}$ artigo objetiva discutir a interface entre o planejamento urbano e a educação ambiental, apoiando-se sobre as três dimensões básicas do desenvolvimento sustentável. O debate sobre a inserção dos conceitos relacionados à sustentabilidade e educação ambiental, diante dos novos desafios que lhe são correlatos, a cada dia está mais em voga na sociedade. Vários são os meios voltados a sensibilizar e guiar as pessoas para um olhar ambiental, tendo como exemplo as políticas públicas nacionais, estaduais e municipais que contemplam o meio ambiente e o desenvolvimento das cidades. De maneira análoga, certos conselhos profissionais apresentam normativas voltadas para o desenvolvimento sustentável e a boa gestão ambiental nos diversos segmentos profissionais. Além disso, as instituições de ensino, formadoras do capital humano para o mercado de trabalho ou a pesquisa científica, deveriam tomar por obrigação estimular a educação ambiental em seus currículos. Diante do exposto, este artigo busca incentivar a discussão sobre a educação ambiental, no âmbito do planejamento urbano, a fim de indicar de que maneira este olhar pode contribuir para o desenvolvimento sustentável.

Palavras chave: Educação; Planejamento urbano; Sustentabilidade.

\section{ABSTRACT}

This article aims to discuss the interface between urban planning and environmental education, focusing on the three basic dimensions of sustainable development. The debate about the insertion of concepts related to sustainability and environmental education, given the new challenges related to them, are becoming more and more popular in society. There are several ways to raise awareness and guide people to an environmental perspective, taking as an example several national, state and municipal public policies that govern the environment and the development of cities. As well, certain professional councils present legal normative for the sustainable development and the good environmental management in different professional segments. In addition to these, the educational institutions that form the human capital for the labor market or scientific research, should take as an obligation to stimulate environmental education in their curricula. In view of the above, this article searches to increase the discussion on environmental education, into the urban planning field in order to indicate how this approach can contribute towards sustainable development.

Keywords: Education; Urban planning; Sustainability.

\section{RESUMEN}

El artículo busca discutir la interfaz entre la planificación urbana y la educación ambiental, basado en las tres dimensiones del desarrollo sostenible. El debate sobre la inserción de los conceptos relacionados con la sostenibilidad y la educación ambiental, frente a los nuevos desafíos relacionados a estos, cada día están más en boga en la sociedad. Varios son los medios para sensibilizar y guiar a las personas hacia una mirada ambiental, teniendo como ejemplo, diversas políticas públicas nacionales, estatales y municipales que rigen el medio ambiente y el desarrollo de las ciudades. Como también, legislación de consejos profesionales, trayendo normativas para el desarrollo sostenible y la buena gestión ambiental en los diversos segmentos profesionales. Además de estos, citamos aquí las instituciones de enseñanza que son las entidades fomentadoras del capital humano para el mercado de trabajo o investigación científica y tiene por obligación incentivar la enseñanza de la educación ambiental en sus currículos. Frente a lo expuesto, este artículo se justifica por traer la discusión sobre la educación ambiental y planificación urbana y como éstas, pueden caminar en pro del desarrollo sostenible.

Palabras clave: Educación; Planificación urbana; Sostenibilidad. 


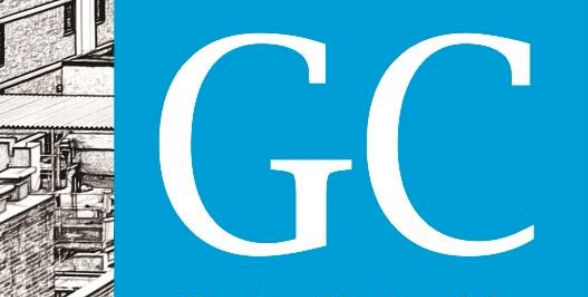

Revista Nacional de

\section{POR UMA EDUCAÇÃO AMBIENTAL TRANSFORMADORA EM PROL DO DESENVOLVIMENTO SUSTENTÁVEL}

Atualmente, diante da crescente urbanização, a capacidade dos países considerados em desenvolvimento, como o Brasil, de oferecer serviços básicos (habitação, saneamento, saúde e transportes, dentre outros), não tem acompanhado as demandas da população de baixa renda. Assim, não somente são necessárias políticas de inclusão social adequadas, como também se torna urgente a busca de alternativas educacionais que permitam o desenvolvimento de uma percepção abrangente da questão ambiental. Tais alternativas devem proporcionar a compreensão das interrelações entre os diferentes aspectos que envolvem a realidade, sejam eles físicos, humanos, econômicos, sociais, políticos ou culturais.

Desde a década de 1970, a educação ambiental já compunha as ementas educacionais, mesmo quando se caracterizava por uma formação conservadora, que privilegiava o modelo tecnicista com formato disciplinar. Na época, tal modelo tinha como objetivo a facilitação do caminho informacional para a aprendizagem efetiva, no entanto, dificultava sua integração às demais áreas do saber.

Após a Conferência das Nações Unidas sobre o Meio Ambiente e o Desenvolvimento (CNUMAD) conhecida como RIO-92, a educação ambiental passou a ter outra perspectiva, ao romper o paradigma tecnicista para assumir uma postura mais crítica e objetiva, em que as dinâmicas multidisciplinar e interdisciplinar sobre o indivíduo e o ambiente devem ser incorporadas à formação ambiental. Dessa maneira, é necessário contemplar questões socioeconômicas, culturais, políticas, históricas e ecológicas, para promover uma atitude emancipatória do ser humano em sua relação com o meio ambiente.

As instituições de ensino são as maiores responsáveis pela educação do indivíduo e, consequentemente, da sociedade. Adotar um modelo de educação apoiado nos aspectos ambientais e no desenvolvimento sustentável mostra-se uma decisão pertinente, dentro dos diferentes modelos de desenvolvimento da sociedade. Nesse sentido, a Lei $n^{\circ} 9.795$ de 27 de abril de 1999, que institui a Política Nacional de Educação Ambiental, entende por educação ambiental "os processos por meio dos quais o indivíduo e a coletividade constroem valores sociais, conhecimentos, habilidades, atitudes e competências voltadas para a conservação do meio ambiente" (BRASIL, 1999).

Por isso, a Educação Ambiental é vista e entendida como um processo e não como um fim em si mesmo. A lei em questão estabelece que a educação ambiental deva ser desenvolvida como uma prática educativa integrada, contínua e permanente em todos os níveis e modalidades do ensino formal, mas, não como disciplina específica incluída nos currículos escolares. No que se refere à educação da população, em geral, o trabalho educativo neste âmbito deve ser desenvolvido através de uma ação transformadora que visa a formar os sujeitos críticos com relação à realidade em que estão inseridos e que está centrada em três vertentes principais, a saber: ação cultural, movimento de educação popular e teoria de educação (PALUDO, 2012). Apesar de diversas disciplinas abordarem o tema, a educação ambiental pode ser enquadrada 


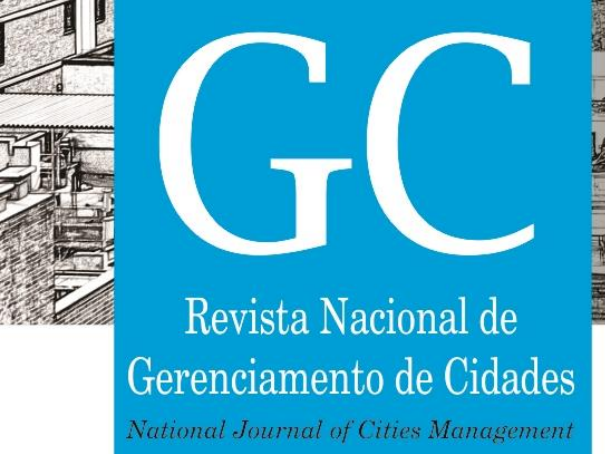

Segundo Canepa (2007) esse diálogo é um imperativo democrático como fórmula de subversão da hegemonia capitalista impositiva de valores, muitas vezes globais, a valores mais próximos das necessidades sociais locais. Tendo em vista as demandas sociais, o planejamento urbano, com vistas ao desenvolvimento sustentável, deve promover um amplo debate sobre a questão ambiental nas cidades, de modo que a ferramenta da educação ambiental possa trazer o conhecimento necessário ao desenvolvimento do ser social. Neste ponto, os debates versariam sobre a dialética existente entre o progresso necessário da ótica ambiental/urbana e a equidade na discussão social, que envolve as forças hegemônicas, os planejadores urbanos e demais atores sociais.

\section{PLANEJAMENTO URBANO E DESENVOLVIMENTO SUSTENTÁVEL: UMA DISCUSSÃO SOBRE A EDUCAÇÃO AMBIENTAL PARA O BEM-ESTAR SOCIAL}

A recomendação no 8 do documento resultante da Conferência de Tbilisi sobre Educação Ambiental, em 1977, chama atenção para algumas classes de profissionais que devem receber atenção especial em sua formação, conforme segue:

Setores da população aos quais está destinada a Educação Ambiental:

1 - Educação do público em geral;

2 - Grupos profissionais ou sociais específicos, especialmente aqueles que tenham repercussões importantes no meio ambiental engenheiros, arquitetos, administradores e planejadores industriais, sindicalistas, médicos, políticos e agricultores. Diversos níveis de educação formal e não-formal deverão contribuir para essa formação. 3 - A formação de determinados grupos de profissionais e cientistas: essa formação está destinada a quem se ocupa de problemas específicos do meio ambiente - biólogos, ecólogos, hidrólogos, [...]engenheiros, arquitetos, oceanógrafos, [...], etc. - e deve compreender um componente interdisciplinar.

(Algumas Recomendações da Conferência Intergovernamental sobre Educação Ambiental aos Países Membros - Recomendação no 8 Tbilisi, CEl, de 14 a 26 de outubro de 1977).

Considerando que profissionais de diversas áreas trabalham com planejamento urbano, a recomendação de Tbilisi se aplica com muita propriedade a projetos que envolvem diferentes atores em formação. Porém, ao se pensar em um tipo de planejamento/gestão urbanoambiental que se oriente pelos preceitos da transdisciplinaridade e participação social, proposta pela Educação Ambiental, estes projetos devem ser ampliados de forma a incluir cidadãos, em geral, bem como todo tipo de profissional que possa contribuir, direta ou indiretamente, com enfoques diferenciados e diversificados da temática. 


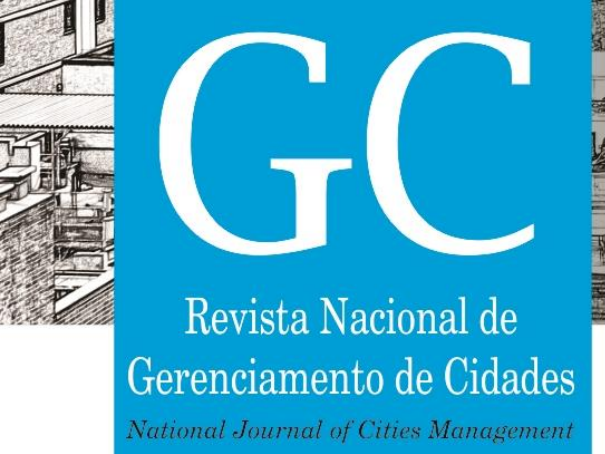

Para o CAU/BR (2016), a cidade é o suporte físico para o desenvolvimento ambiental, econômico e social. Desse modo, o planejamento deve se antecipar aos problemas com uma visão de longo prazo, pois sua inexistência representa uma condenação às futuras gerações. Neste caso, a educação ambiental, pode dar suporte à tríade do desenvolvimento sustentável, trazendo conhecimento e agregando valor às ações dos atores sociais que planejam a cidade.

O Programa Nacional de Educação Ambiental (2005) aponta que ocorrerá um fortalecimento do papel de cada indivíduo que educa, ou se educa, para a construção de sociedades capazes de gerir seus conflitos sociais, econômicos e ambientais. Portanto, os conceitos baseados na Educação Ambiental se apresentam como uma ferramenta essencial na formação do ser social, em particular, dada a possibilidade de sua produção atingir grande parte dos cidadãos.

Acserald (1999) alerta que as matrizes discursivas que articulam as questões ambiental e urbana fazem parte de um jogo de poder em torno da apropriação do território e de seus recursos, que têm por objetivo legitimar ou deslegitimar discursos e práticas sociais.

Em suas próprias palavras, Lefebvre (2002) faz uma "crítica radical no plano teórico" ao urbanismo, afirmando que esta atividade estaria mais próxima da ilusão quando se autodenomina arte e ciência, técnica e conhecimento. Diz Lefebvre:

Existem diversos urbanismos, o dos humanistas, o dos promotores imobiliários, o do Estado e dos tecnocratas. Os primeiros propõem utopias abstratas; os segundos vendem urbanismo, ou seja, felicidade, 'estilo de vida', 'status'; quanto aos últimos, sua atividade, assim como a do Estado, dissocia-se em vontade e representação em instituições e ideologias. As pressões simultaneamente exercidas pelos dois aspectos do urbanismo estatista em nada lhe conferem o caráter unitário e a organização coerente que ele próprio se atribui. Poder-seá objetar: 'sem os urbanistas seria o caos'. Ora, exatamente, é o caos, sob uma ordem imposta. O pensamento urbanístico, na ausência de um método apropriado (dialético), não pôde dominar o duplo processo, altamente complexo e conflitante: industrialização urbanização. (LEFÉBVRE, 2002 p.139)

É necessário fazer uma reestruturação nas formas de pensar o planejamento urbano/ambiental contemplando a dialética, a participação popular e a transdisciplinaridade, de forma a se estudar o espaço urbano de maneira sistêmica, permitindo uma melhor compreensão das inter-relações existentes entre os diversos setores envolvidos no planejamento urbano.

\section{PLANEJAMENTO URBANO, EDUCAÇÃO AMBIENTAL E DESENVOLVIMENTO SUSTENTÁVEL: UM OLHAR SOBRE ESTUDOS REALIZADOS}

A abordagem de temas relacionados com a sustentabilidade, no cotidiano escolar, qualifica os envolvidos para que desenvolvam uma posição consciente frente à crise socioambiental que 


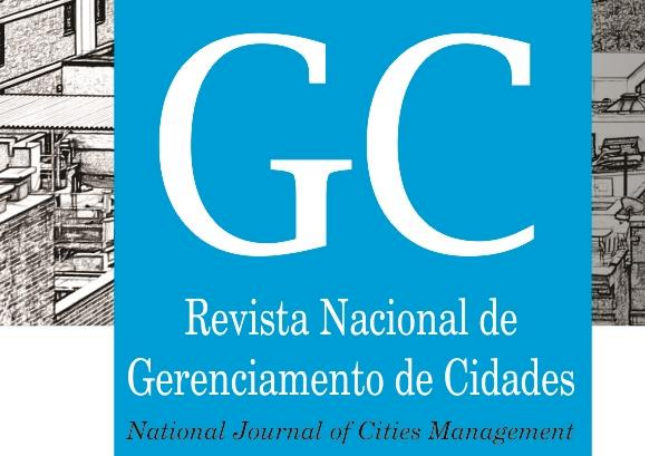

vivemos, tendo como foco a alteração de hábitos e práticas sociais e a formação de cidadãos mobilizados pelas causas do desenvolvimento sustentável (JACOBI, 2005).

Sendo assim, é importante que a discussão aqui apresentada aponte modelos, onde tenha sido utilizada a educação ambiental no planejamento urbano, com um enfoque social. Espera-se, assim, mostrar a importância da educação ambiental para o desenvolvimento sustentável e o bem-estar social, no planejamento urbano, como também apontar deficiências no ensino superior sobre as abordagens ambientais. Para isso, segue uma discussão que traz aportes sobre estudos relacionados com educação ambiental e planejamento urbano, além de mostrar percepções e comportamentos acerca do papel dessa ferramenta para a prática do planejamento da cidade.

Nas atividades práticas desenvolvidas pelo Projeto Arquitetos do Saber, Almeida Netto et al. (2017) destacam que, em relação à educação ambiental, voltada à população em geral, são enfatizadas ações que levam em consideração o saber popular, as tradições e a cultura local. Diante de tais ações, constatou-se que, por meio da participação na extensão, puderam crescer socialmente. As práticas permitiram o desenvolvimento de reflexões, próprio dos processos de comunicação, quando ocorre a participação ativa dos sujeitos e a valorização do saber local, no planejamento urbano.

No estudo de planejamento urbano sobre os Resíduos Sólidos da Construção (RSC), Bescorovaine et al. (2016), ao analisar os resultados obtidos, notaram a necessidade de implementação de uma proposta pedagógica diferenciada e eficaz no encaminhamento da temática ambiental nas instituições de ensino. Tal proposta tem como finalidade contribuir para a reflexão crítica sobre os valores ambientais que devem permear as atitudes dos estudantes. Essa proposição ocorre pelo fato da amostra ter tido em sua grade curricular disciplinas que abordam a temática, porém, na prática, acabam agindo de forma contraditória ao conteúdo aprendido em sala de aula.

No contexto da disseminação de informações referentes à sustentabilidade, que buscam a geração de hábitos e opiniões a fim de interferir de forma crítica no modelo de desenvolvimento vigente, os estabelecimentos de ensino e os educadores entram na discussão como mediadores dessas reflexões. Em pesquisas sobre extensão universitária e sustentabilidade urbana, Caumo e De Marque (2015) afirmam que a educação ambiental, em projetos de extensão, corrobora a formação acadêmica dos graduandos envolvidos, complementando a formação do cidadão na sociedade, pois, para muitos a universidade é o último grau de construção do ser social.

Considera-se que a extensão proporciona a oportunidade de troca de experiências e de reflexão coletiva, objetivando a disseminação e a ampliação dos saberes de ambas as partes. É essencial que as Instituições de Ensino Superior voltadas para a questão ambiental, além do ensino de conteúdos sobre água, lixo, reciclagem, busquem promover uma transformação nos valores e crenças ambientais dos estudantes. Dessa forma, estarão contribuindo para desenvolver um comportamento ambiental responsável, já que são estes alunos que futuramente planejarão a cidade e os espaços urbanos, bem como influenciarão pessoas que, direta ou indiretamente, serão influenciadores sociais nas dinâmicas dos projetos urbanos. 


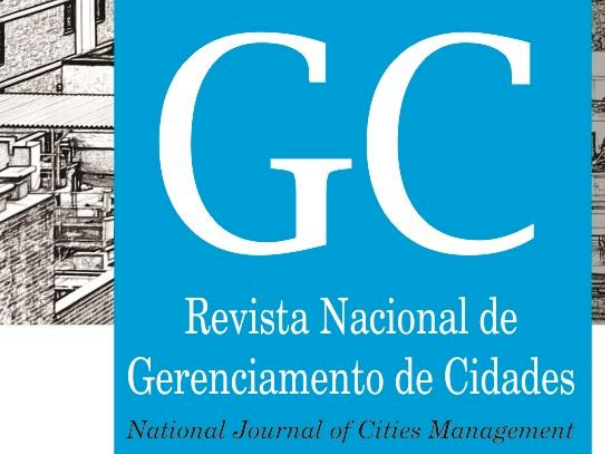

Segundo Souza (2014) as discussões sobre a educação ambiental proporcionaram o debate sobre questões relacionadas à crise social, política e econômica, cristalizada nos pressupostos capitalistas. Assim, a Educação Ambiental tornou-se uma alternativa para sensibilizar a sociedade, em vista das questões ambientais e urbanas, levando-a à percepção crítica e reflexiva sobre a complexidade dos problemas que afetam o ambiente nos dias de hoje.

Para Silveira (2009) a educação ambiental deve ser o marco inicial de qualquer projeto em planejamento urbano. Dessa forma, poderá fortalecer os debates comunitários, envolvendo pessoas e entidades representativas na sociedade como escolas, associações e clubes. 0 objetivo será, portanto, de envolver a comunidade e ao mesmo tempo motivá-la a participar das tomadas de decisões coletivas. A praxis da educação ambiental, no planejamento urbano, pode ser emancipadora para o desenvolvimento social e econômico, com base em iniciativas que reavaliem o papel da cidade e a participação de cada cidadão na transformação do comportamento dos indivíduos.

A Educação Ambiental é um ponto de partida fundamental para uma participação social concreta, nos processos de planejamento e gestão urbana. Compreende-se, então, porque a Educação Ambiental age como transformadora do ser social, contribuindo efetivamente nas ações de planejamento urbano.À guisa de conclusão, pode-se afirmar que a proposta da educação ambiental é capaz de estimular discussões de maneira a problematizar vários aspectos da sociedade urbana atual, dentre os quais o modelo de desenvolvimento econômico, social e cultural e a responsabilidade ambiental-urbana. Assim, a educação ambiental apresenta-se como uma importante ferramenta, em apoio aos planejadores na tarefa de fomentar a discussão na sociedade sobre o desenvolvimento urbano sustentável.

\section{AGRADECIMENTOS}

Agradeço ao grupo de pesquisa LEPUR - Laboratório de Estudos Periurbanos (LEPUR/CNPQ/UFPE), é a todos os seus integrantes, pelo apoio a pesquisa e orientações.

\section{REFERÊNCIAS}

ACSELRAD, Henri. Discursos da sustentabilidade urbana. n. 1. Revista Brasileira de Estudos Urbanos e Regionais, Rio de Janeiro, n. 1, 1999, p.79-89.

ALENCASTRO, Maria Alice et al. Contratações sustentáveis na administração pública brasileira: a experiência do Poder Executivo Federal. v. 48. Revista de Administração Pública, Rio de Janeiro, 2014, p. 207-236.

ALMEIDA NETTO, Tatiane et al. A educação como meio de transformação social: o projeto Arquitetos do Saber. $N^{\circ}$ 2. Revbea, São Paulo, 2017, p. 23-33. 


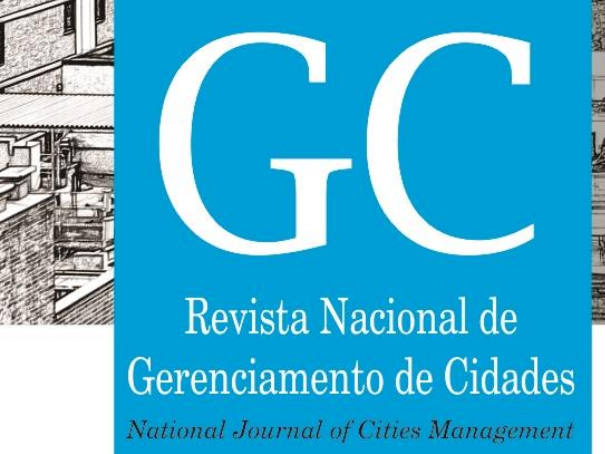

BESCOROVAINE, Wellington et al. Comportamento pró-ambiental e descarte de resíduos sólidos por estudantes de arquitetura: apontamentos para a educação ambiental. $\mathrm{N}^{\circ} 2$. Rev. Geogr. Acadêmica, 2016, p. 105 - 115.

BILAR, Alessandra Bezerra Correia et al. Sustentabilidade de assentamentos no entorno de unidades de conservação: o caso do Parque Estadual Mata da Pimenteira em Serra Talhada/PE. v. 7. Sustentabilidade em Debate, Brasília, 2016, p. 195-211.

BONZI, Rámon Stock. Meio século de primavera silenciosa: um livro que mudou o mundo. $\mathrm{N}^{\circ}$ 28. Revista Desenvolvimento e Meio ambiente, Curitiba, 2013, p. 2017-2015.

BRASIL. Política Nacional de Educação Ambiental. Brasília, 1999. Disponível em: http://www.planalto.gov.br/CCIVIL/LEIS/L9795.htm. Acesso em: 09 mai. 2018.

BRASIL. Programa Nacional de Educação Ambiental. Brasília, 2005. Disponível: http://portal.mec.gov.br/secad/arquivos/pdf/educacaoambiental/pronea3.pdf. Acesso em 09 mai. 2018.

CANEPA, Carla. Cidades sustentáveis: o município como lócus da sustentabilidade. 1. Ed. São Paulo: RCS, 2007, 63 p.

CAUMO, Henrique Luis Viecelin; DE MARQUE, Luciane Massaro. A extensão universitária na arquitetura e urbanismo e engenharia ambiental: disseminação da sustentabilidade e a construção da cidadania. № 01 . Revista de extensão da universidade de Cruz Alta. 2015, p. 108122.

CIDREIRA-NETO, Ivo; RODRIGUES, Gilberto. Relação homem-natureza e os limites para o desenvolvimento sustentável. $N^{\circ} 2$. Revista Movimentos Sociais e Dinâmicas Espaciais. 2017, p. $142-156$.

CAU - BR. Carta compromisso do Conselho de Arquitetura e Urbanismo do Brasil sobre a nova agenda urbana - HABITAT III. 2016. Disponível em: http://www.caubr.gov.br/prefeitos/CARTA_CAU_HABITAT_III_portugu\%C3\%AAs.pdf. Acesso em 24 mai. 2018.

EUROMONITOR. Educação Ambiental em defesa e recuperação do rio São Francisco e seus afluentes, com foco no Estado da Bahia. (2016). Disponível em: https://https://www.ecodebate.com.br/2016/05/02/educacao-ambiental-em defesaerecuperacao-do-rio-sao-francisco-e-seus-afluentes-com-foco-no-estado-da-bahia-artigodedebora-andrade/. Acesso em 23 mai. 2018.

HOBSBAWM, Eric. Era dos extremos: o breve século XX - 1914-1991. 3 ed. São Paulo: Companhia das Letras. 1995, $598 \mathrm{p}$.

JACOBI, Paulo. Educação ambiental: o desafio da construção de um pensamento crítico, complexo e reflexivo. v. 31. Educação e Pesquisa, São Paulo, 2005, p. 233-250. 
